\title{
THIOPENTONE/LIDOCAINE ANAESTHESIA FOR PNEUMOENCEPHALOGRAPHY
}

\author{
P. RAUDZENS, M.D., F.R.C.P.(c) AND A.F.D. CoLE, M.D., F.R.C.P.(c)*
}

General anaesthesIa for pneumoencephalography presents the anaesthetist with a technical problem that has not been solved satisfactorily. The anaesthetic administered should be tailored to meet the demands of patient safety, comfort, possibly increased intracranial pressure and unusual positioning that is necessary during the study. It should also provide a quiet patient for the radiologist to obtain his films quickly and efficiently, and should be easy to administer, with a telative absence of disturbing side effects, to be acceptable to the anaesthetist.

We have studied the use of thiopentone and lidocaine infusion to provide general anaesthesia during pneumoencephalography and have found it better suited to satisfy the demands of the procedure than other reported techniques. ${ }^{1-7}$ We also monitored cerebro-spinal fluid pressure changes during pneumoencephalography, and suggest possible relationships between cerebro-spinal fluid pressure responses, and altered cerebro-spinal fluid dynamics.

\section{Methods and Materials}

Twenty-three consecutive unselected patients were studied. Informed consent was obtained to monitor cerebro-spinal fluid pressure, arterial blood gases, arterial blood pressure, electrocardiogram and respiratory pattern for the duration of each study. Blood was also sampled for analysis of drug levels of thiopentone and lidocaine in each patient. $\dagger$

Cerebro-spinal fluid pressure was recorded with a 20-gauge lumbar spinal needle connected by sterile, saline-filled tubing to a Statham pressure transducer fixed at the level of the foramen magnum. Initially the lumbar needle was placed one interspace above the needle used by the radiologists for air injection. However, the occasional presence of epidural air, presumably caused by air leaking through the other dural hole, forced us to use only one lumbar needle for both pressure recording and air injection. With the radiologists' cooperation, after each injection the tubing was filled with previously aspirated cerebro-spinal fluid and adequate recordings could be made. Care was taken not to spill any fluid.

Arterial pressure was recorded continuously by attaching a Statham transducer to a radial artery cannula (20-gauge Angiocath) inserted under local anaesthesia

${ }^{\circ}$ From the Department of Anaesthesia, Wellesley Hospital, Toronto and the University of Toronto.

†Thiopentone blood levels were estimated for us by Abbott Laboratories, Chicago. Lidocaine blood analysis was done by Astra Chemicals Ltd., Mississauga.

Canad. Anaesth. Soc. J., vol. 21, no. 1, January 1974 
prior to induction. Adequate collateral circulation was confirmed prior to cannulation.

Electrocardiogram leads were attached prior to induction.

A strain gauge attached to the patient's chest and connected to another Statham transducer was used to record respiratory excursions.

These four parameters were displayed continuously on a Beckman polygraph recorder after the machine had been calibrated for each yariable, prior to the study.

Arterial blood from the radial artery was sampled four times in each patient, both for arterial blood gas values and drug levels of thiopentone and lidocaine: the times were pre-induction, at the beginning of spontaneous respiration, one hour after induction, and upon awakening in the Recovery Room.

The patients were premedicated with diazepam 5 or $10 \mathrm{mgm}$ and atropine 0.6 mgm one hour before anaesthesia.

After the patient was readied for recording, anaesthesia was induced with an intravenous sleep dose of thiopentone (125 to $350 \mathrm{mgm}$ ) and relaxation obtained by succinylcholine, $1 \mathrm{mgm} / \mathrm{kg}$ body weight. The patient was oxygenated and, prior to intubation, the trachea was carefully sprayed with topical solution containing $40 \mathrm{mg}$ of lidocaine. Ventilation was controlled with oxygen until spontaneous respiration returned. At this time anaesthesia was maintained with an infusion containing $1.5 \mathrm{~g}$ thiopentone and $0.2 \mathrm{~g}$ lidocaine in $500 \mathrm{cc}$ of normal saline. The drip rate was adjusted to keep the patient quiet and asleep without depressing respiration or blood pressure. Oxygen at $4 \mathrm{~L} / \mathrm{min}$ was added to the room air breathed by the patient. The patient could then be positioned for X-rays and air injection. At the end of the procedure, the patient was allowed to wake up in the Recovery Room, where the arterial line was removed. Follow-up the next day included testing for return of pulsation in the cannulated radial artery and questioning of the patient about the acceptability of the anaesthetic.

\section{RESULTS}

Of the 23 patients studied, 21 had the thiopentone and lidocaine infusion administered, one had a halothane/oxygen anaesthetic, and one had only local anaesthetic injected subcutaneously at the lumbar puncture site. This last patient's mental state was so depressed that she did not need a general anaesthetic. Adequate pressure tracings were obtained in 12 of the 23 patients, but blood samples were obtained in all 23 patients. In this unselected group, there were 12 females and 11 males. Ages ranged from 22 to 73 years, with a mean of 46 . In none of these patients was there clinical evidence of increased intracranial pressure. The clinical and radiological diagnoses were cerebral atrophy 4, epilepsy 8 , trauma 2 , undiagnosed headache 6 and N.A.D. 3.

The most obvious result was that the thiopentrone/lidocaine infusion anaesthetized patients satisfactorily for pneumoencephalography. All patients remained asleep and quiet, provided that adequate amounts of drug were infused. Volumes of solution ranged from 250 to $800 \mathrm{cc}$. The range of drug concentrations in the serum are indicated in Table I.

The volume of drug infused was related to the length of the procedure, the 
TABLE I

Serum Drug Concentrations

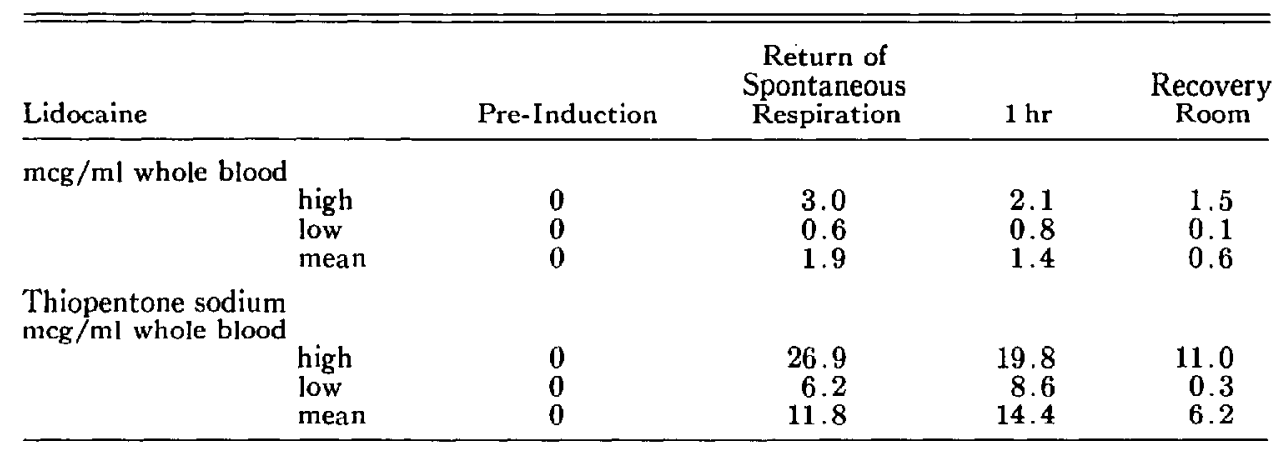

patient's size and the patient's age. For the average 2-hour pneumoencephalogram approximately $500 \mathrm{cc}$ of solution was required for a $65 \mathrm{~kg}$ patient. This works out to about $1 \mathrm{cc} / \mathrm{kg}$ body weight $/$ minute of drug infused, or $3 \mathrm{mg}$ thiopentone and $0.4 \mathrm{mg}$ lidocaine per $\mathrm{kg}$ body weight each minute.

The anaesthetic period was free of side-effects. No arrhythmias, hypotension or respiratory depression were seen, despite the extreme positional changes necessary. The radiologist was able to complete his study in 1 to 2 hours, depending on the extent of his investigation, and the films were satisfactory. Awakening time, as judged by response to verbal command, was 1 to 2 hours. The post-anaesthetic period was generally free of disturbances, although three patients were nauseated and all complained of headache. No recall or discomfort was volunteered by patients the day following the procedure. There were no problems with the radial artery cannulation site.

Blood gas values showed that the unassisted respirations were adequate. The ranges in values reflect the pre-existing pulmonary function of the individual patients, rather than varying anaesthetic levels (Figures la, lb; lc.)

Cerebro-spinal fluid pressures measured agree with previous studies during pneumoencephalography. ${ }^{1,2.8}$ In all Thiopentone/Lidocaine patients, cerebrospinal fluid pressure rose slightly during induction and then returned toward the pre-induction baseline. The enormous pressure changes following air injection were transient, and the pressure returned to pre-injection levels within 10 minutes and usually much more quickly. We also found strikingly increased cerebro-spinal fluid pressure associated with patient rotation, but this was also a transient change. This is displayed in the accompanying graph, and examples of actual records obtained (Figures 2-6).

One interesting observation was the different time course for return of the cerebrospinal fluid pressure to pre-injection levels in some patients. This may indicate different cerebrospinal fluid mechanics in these few patients (Figures 4,5).

For the patient anaesthetized with halothane and oxygen, cerebrospinal fluid pressure is displayed on the same graph with systolic blood pressure (Figure 7). During the pneumoencephalography the patient was left in the brow-down position for about 20 minutes. His blood pressure gradually fell and it was finally 


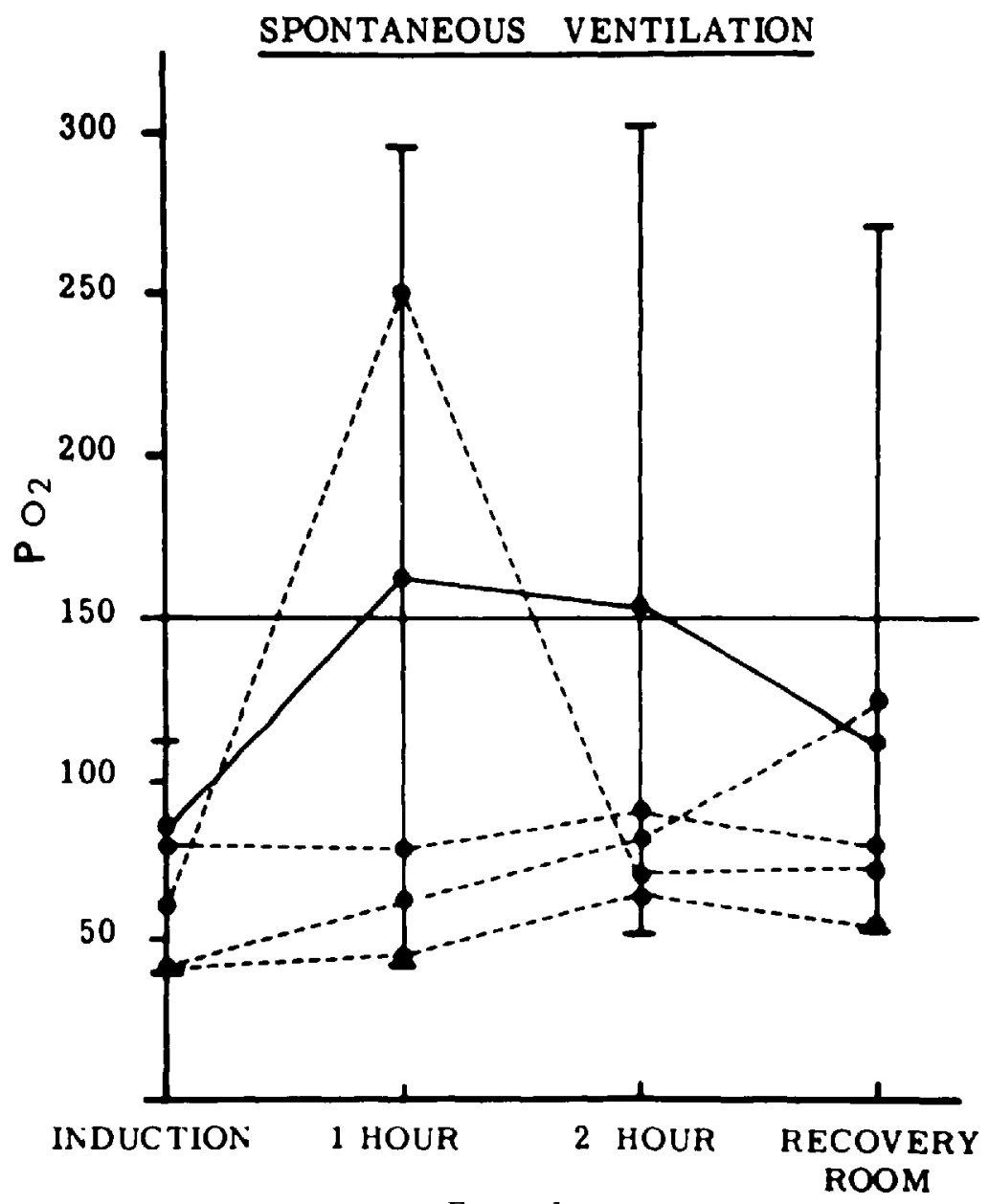

Figure la.

Figune. 1 ( $1 \mathrm{a}, 1 \mathrm{~b}, 1 \mathrm{c}$ ). Arterial blood gas values are plotted at different sampling times during the procedure. The heavy line represents mean values. The four broken lines are values obtained from the same four patients (this is explained in the text).

necessary to "auto-transfuse" him by rotating his position to brow-up, to return the blood pressure to normal levels.

Cerebrospinal fluid pressure was also plotted for the patient who had only local anaesthesia. An alarming increase of pressure was recorded after one injection of air. This was associated with a hypertensive response and an apnoeic period, which passed and returned to normal as cerebrospinal fluid pressure fell (Figures $8 \mathrm{~A}, 8 \mathrm{~B})$.

\section{Discussion}

The choice of thiopentone and lidocaine for anaesthesia was based on several considerations.

Thiopentone infusion has been used safely and effectively for neurosurgical 


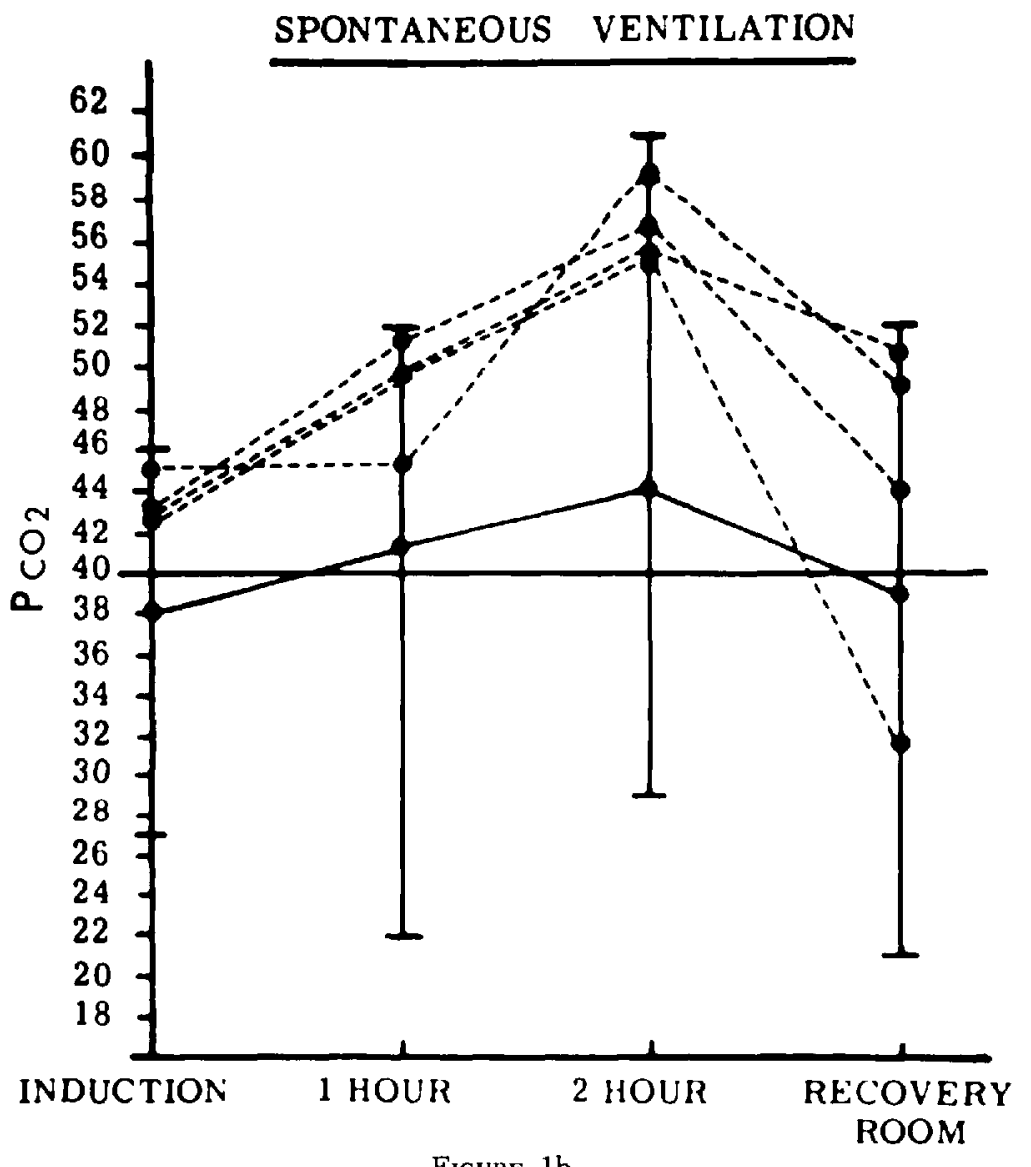

anaesthesia. It is an effective hypnotic, keeping the patient asleep, and it reduces cerebral metabolism without increasing intracranial pressure. ${ }^{9}$ The depth of anaesthesia was regulated by adjusting the rate of infusion. The drug levels we obtained were comparable to Hunter's values of 5 to $7.6 \mathrm{mcg} / \mathrm{ml}$.

Lidocaine was added to our infusion to suppress the cough reflex ${ }^{10}$ and to provide some analgesia without depressing respiration. Lidocaine also independently stimulates respiratory activity, and stabilizes cardiovascular activity. ${ }^{11,21,13,14}$ With the tracheal tube secured in place and tolerated by the patient, the airway was well maintained despite the unusual positions forced by the procedure. Spontaneous respiration was adequate. Monitoring of the respiratory pattern of the patient was a useful clinical indicator that would not have been available with any form of anaesthesia requiring controlled ventilation. The blood levels of lidocaine ${ }^{26}$ obtained were within the usual range of therapeutic serum concentrations for the treatment of cardiac arrhythmias, e.g. 1.5 to $4 \mathrm{mg}$ per litre. ${ }^{15}$

This anaesthetic solution was the sole agent necessary. Only oxygen was added to the inspired air. No nitrous oxide was used and we did not have to worry about increasing the size of the intracranial gas bubble by diffusion of nitrous oxide 


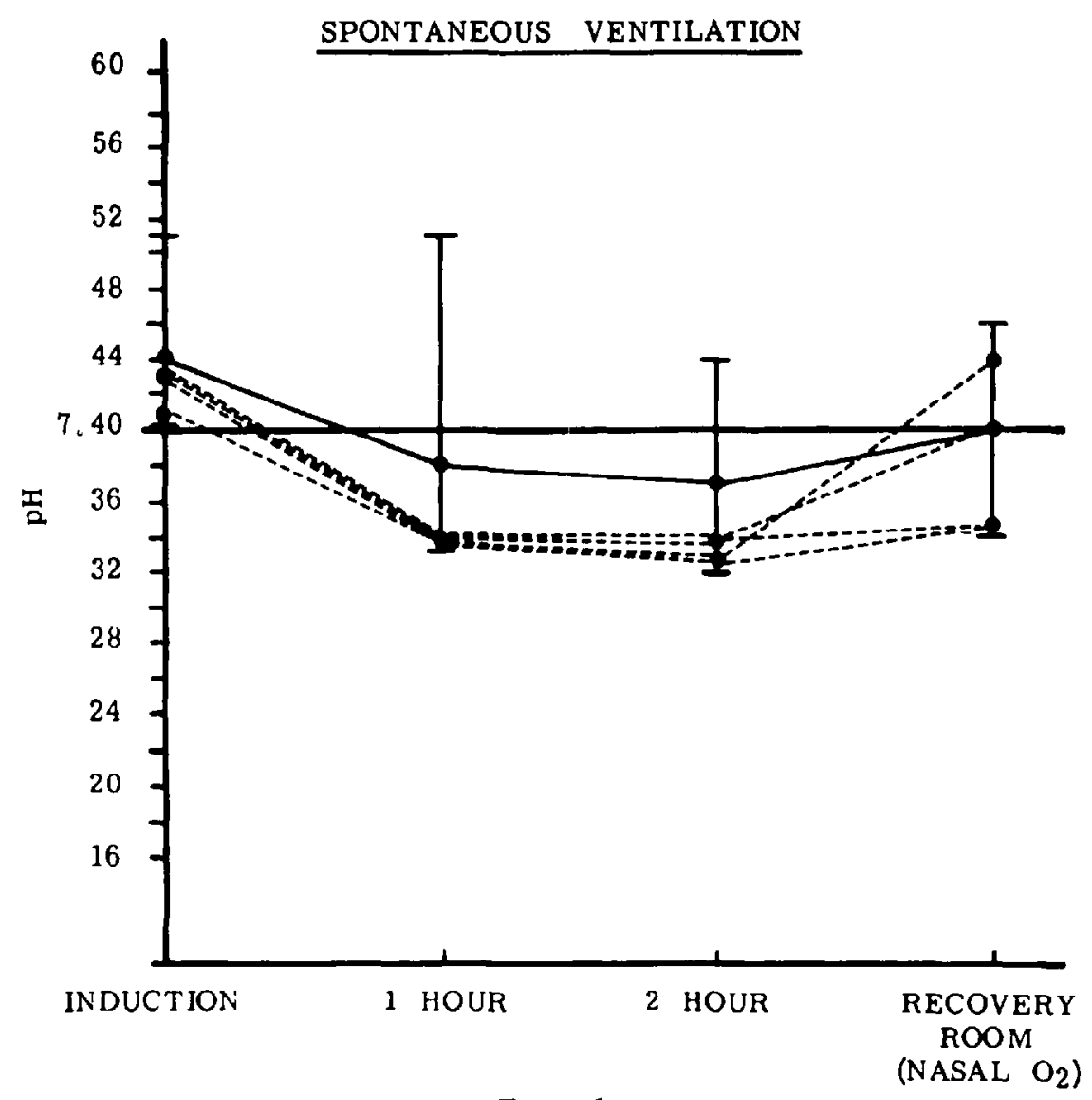

Figure lc.

into the air-filled ventricles with the resulting increase in intracranial pressure. ${ }^{1}$ In a patient with already increased intracranial pressure this further rise may be critical.

We were also able to avoid the potent volatile anaesthetics, which are associated with some increased intracranial pressure. ${ }^{16}$ Of the intravenous agents, Ketamine has been found to increase intracranial pressure as well as to provoke some vomiting or movement during pneumoencephalography; ${ }^{5-7}$ neuroleptanalgesia may seriously depress respiration and cause vomiting and hypotension; ${ }^{3}$ diazepam has been less than satisfactory ${ }^{4}$ because of patient movement or discomfort.

Our experience is that thiopentone and lidocaine infusion proved to be a better anaesthetic for pneumoencephalography than other reported techniques. Subsequently we have used this technique for other procedures with success.

The prolonged awakening time might be criticized. Methohexital or propanidid as a substitute for the thiopentone might hasten postoperative recovery. Postoperative nausea, vomiting and headache were common, and we observed no differences between these patients and those who received other anaesthetics prior to our study. This agrees with other authors. ${ }^{17}$ We did not compare lumbar and intracranial cerebrospinal fluid pressures but this has been done and a consistent 


\section{CSFP DURNG PEG THIOPENTONE/XYLOCAINE}

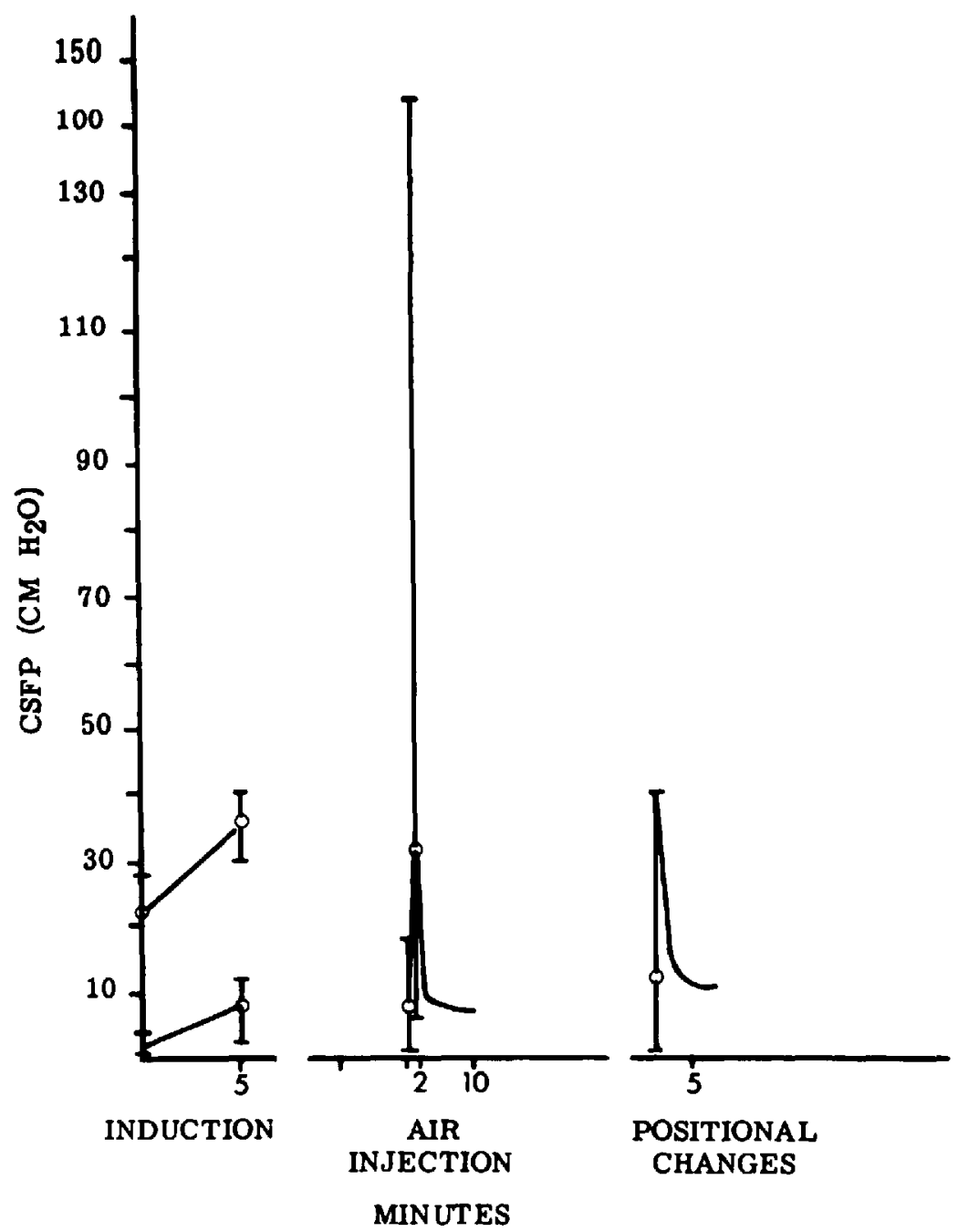

Figure 2. Mean cerebro-spinal fluid pressures (CSFP) are plotted at different periods during the procedure. The decay curve represents mean time to return to pre-air injection levels.

relationship has been demonstrated, provided, of course, that there is open communication. ${ }^{6}$

Our cerebrospinal fluid pressure tracings displayed cardiac and respiratory, fluctuations, as well as a step-wise fall in pressure after air injection described by others. ${ }^{1,18,19}$ The pressure changes recorded were not related to the amount of air injected, but rather to the pre-existing intracranial pressure capacity of the individual patients. Although none of our patients had intracranial space occupying lesions, great differences were obvious in their ability to compensate for the pressure increases due to the intrathecal injection of air, either in the levels of 


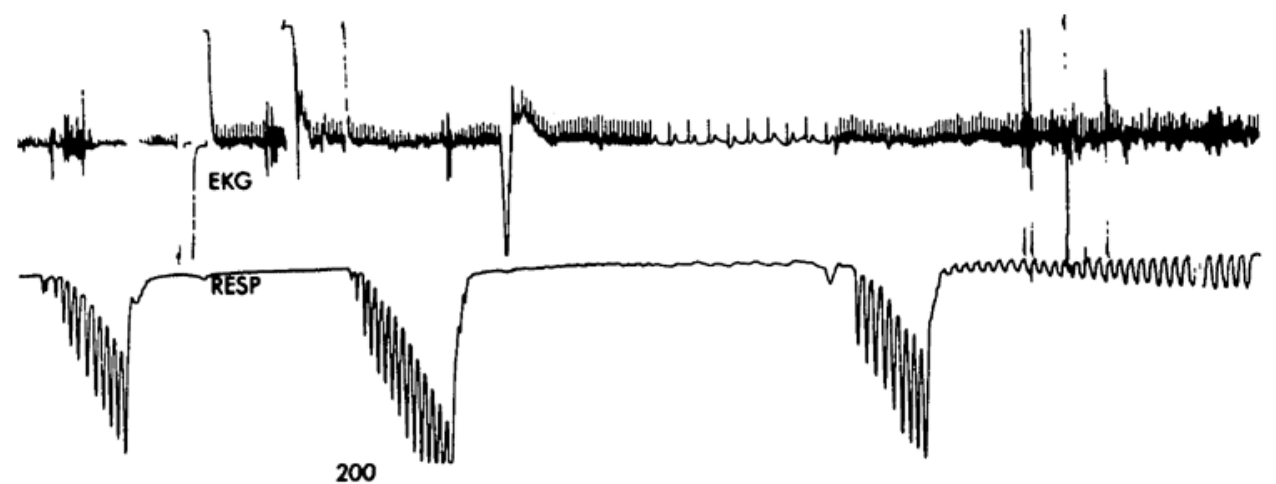

ART. B. P.

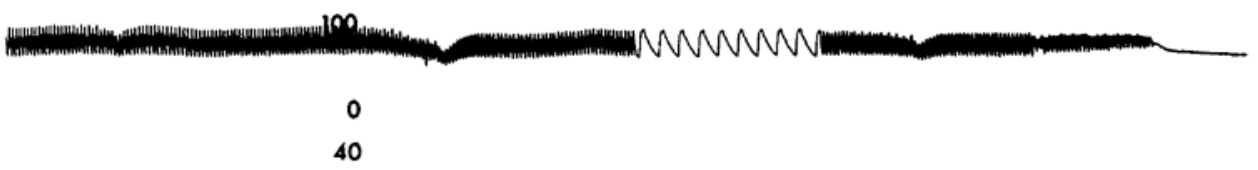

CSFP

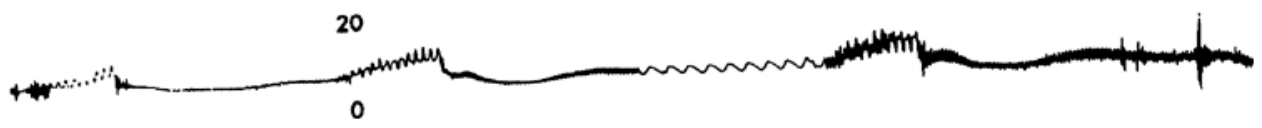

Figune 3. This is a representative record obtained during induction. At mid-record, the trace speed was increased to illustrate the EKG complexes and CSFP fluctuations. The right side of this trace marks the beginning of spontaneous respiration. Arterial B.P. is calibrated in mm. $\mathrm{Hg}$ and CSFP in $\mathrm{cm} \mathrm{H}_{2} \mathrm{O}$. There was some electrical interference recorded on the EKG channel that was not due to the patients condition.

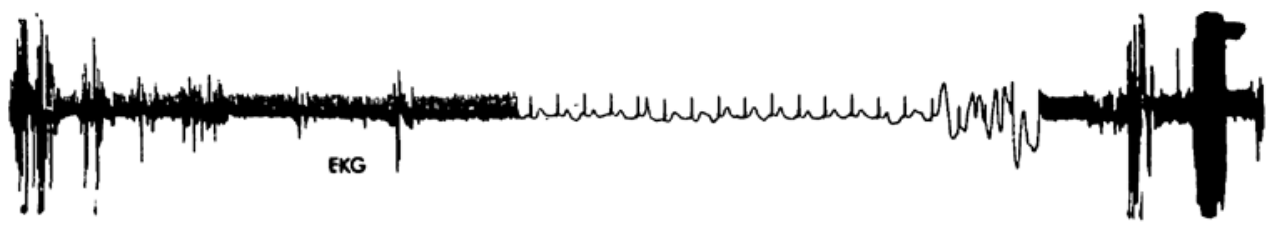

RESP

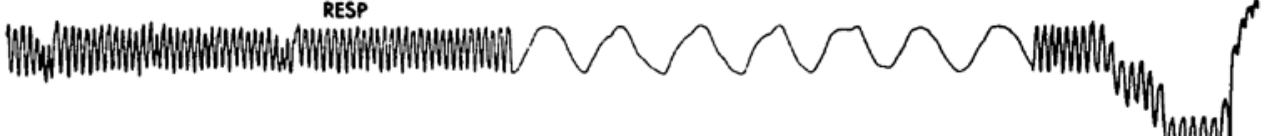

ART. B.P. 200

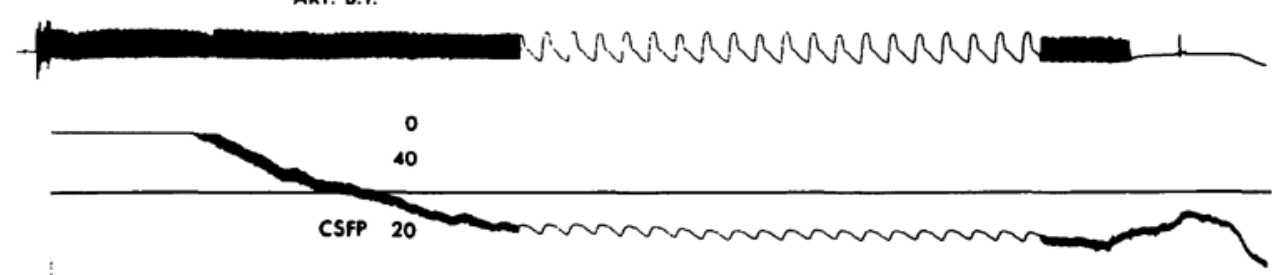

20cc AIR

0

Frgure 4. This is a representative record obtained following the injection of intrathecal air in a patient with a normal PEG. The trace speed was increased to emphasize the CSFP fluctuations. Also note the stepwise fall in CSFP toward pre-air injection levels. Again, the EKG channel was "noisy" and displayed electrical interference. 

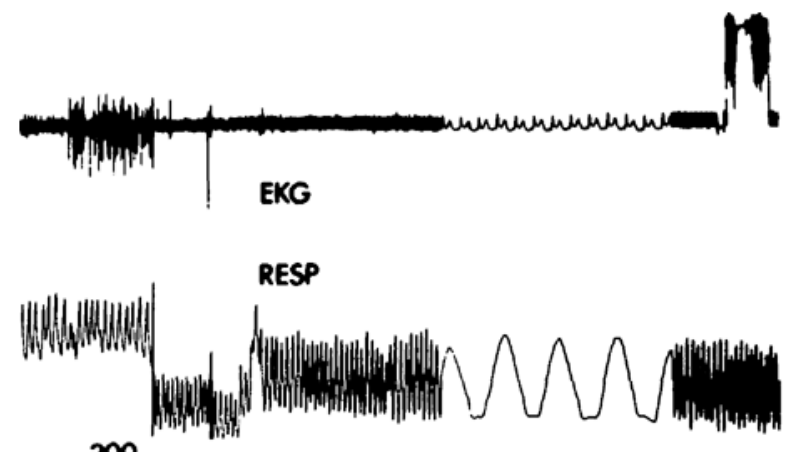

$-200$

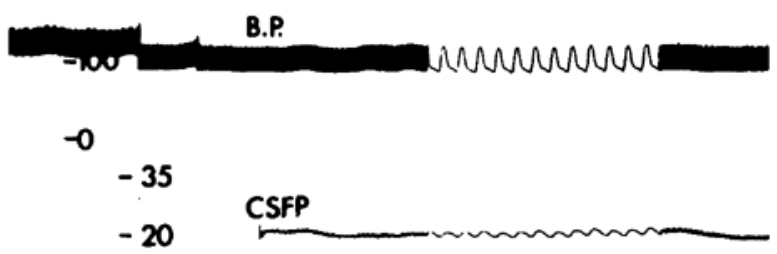

!

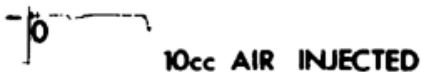

Ficune. 5. This record was obtained from a patient with cerebral atrophy and an enlarged ventricular system to illustrate the delayed time course for CSFP to fall following air injection. This is discussed in the text. Compare this record to that of Figure 4.

EKG

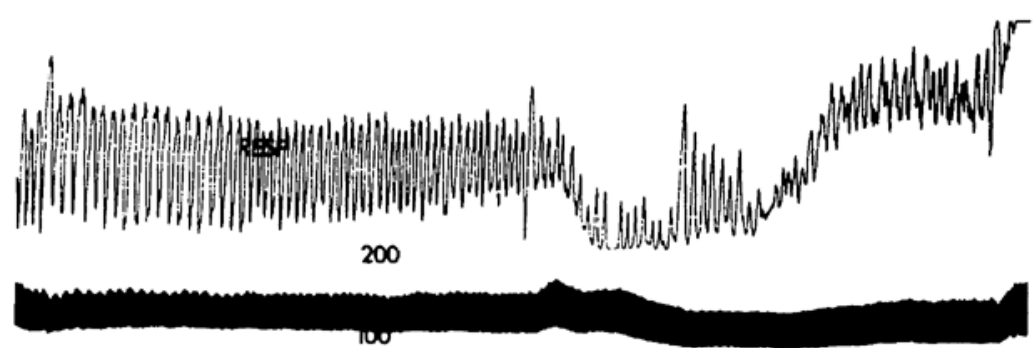

ART. B.P.

0

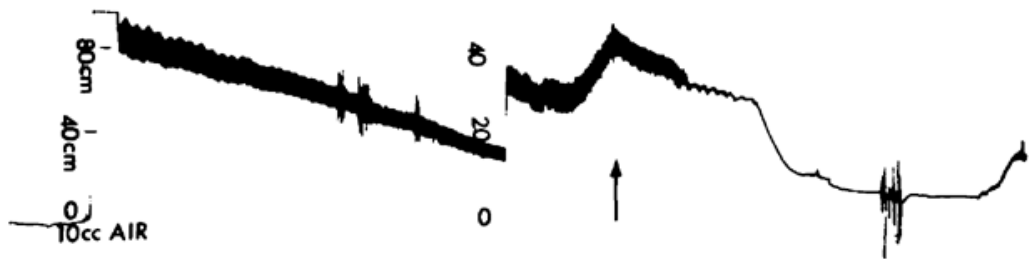

Figure. 6. This record illustrates the CSFP changes associated with a change of the patients position from upright to upside-down. The positional change occurred at the arrow. The calibration of the CSFP channel was changed in mid-trace because of the high initial levels of CSFP following the air injection. 


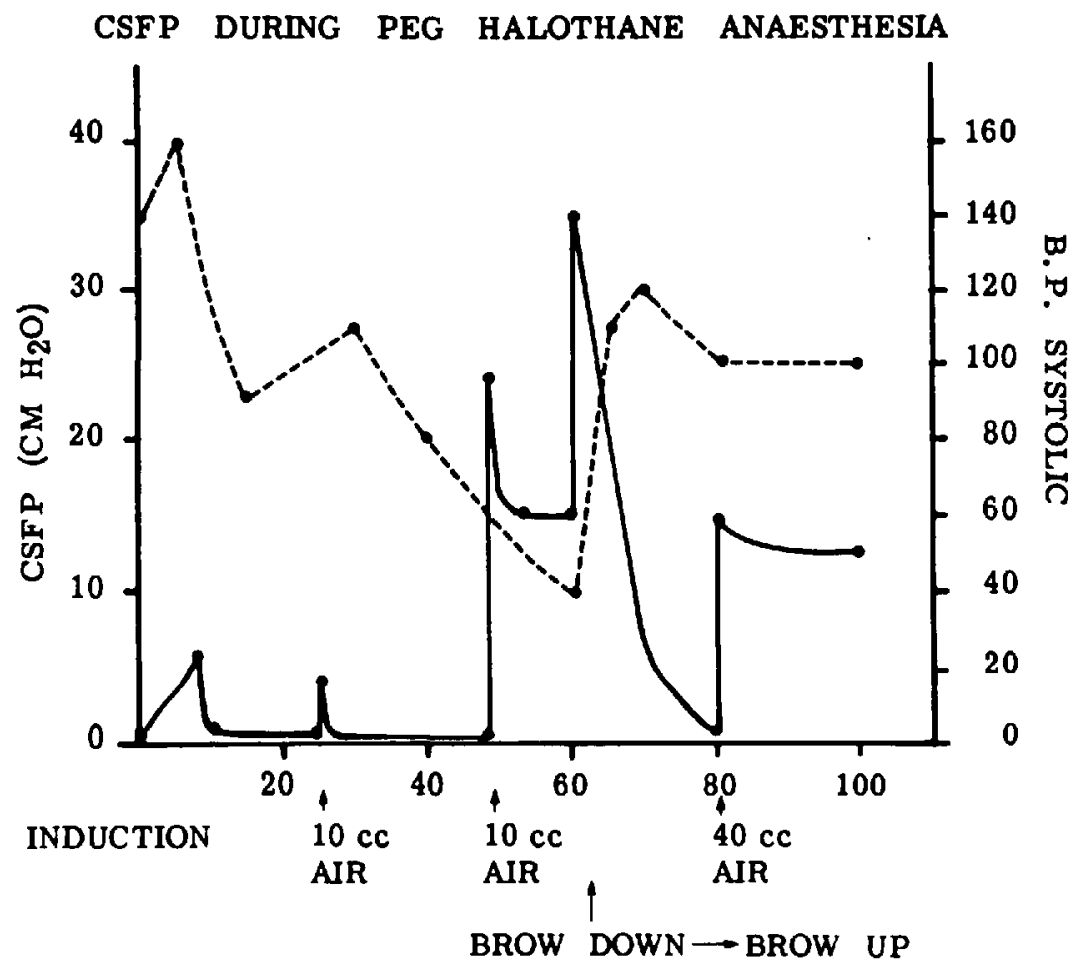

\section{MINUTES}

Figune 7. This graph displays CSFP changes together with systolic arterial pressures (broken line) plotted during the procedure. The patient was left in a brow-down position for about 20 minutes, and his B.P. steadily fell. As he was turned to the brow-up position his B.P. returned to normal. These rapid positional changes are possible in the rotating chair used for PEG.

cerebrospinal fluid pressure reached, or in the time taken for pressure to return to pre-injection levels.

Induction of anaesthesia was associated with a transient, small rise of cerebrospinal fluid pressure. This agrees with other workers. ${ }^{20,21}$ Causes of this pressure rise include stimulation during laryngoscopy, with resulting hypertension and possible $\mathrm{CO}_{2}$ retention, both tending to increase cerebral blood flow.

In patients with normal cerebrospinal fluid pressures, the intrathecal injection of air produced sudden increases of pressure which quickly returned to baseline levels. This pressure increase is presumably buffered by the compressibility of the gas and by some redistribution of cerebral blood volume through the venous outlets from the cranial cavity and through the lumbar epidural venous plexus. It was proposed by Saidman and Eger ${ }^{1}$ that this increased intracranial pressure is compensated by the absorption of CSF and small bubbles of gas by the unidirectional valves ( as described by Welch \& Friedman ${ }^{19}$ ) between the arachnoid villi and draining venous channels. The absorption of the injected air by CSF, dependant on the solubility of the gas in CSF, is a much slower mechanism and plays an insignificant role.

With slowly increasing intracranial volume, the buffering capacity of the 


\section{CSFP DURING PEG LOCAL ANAESTHESIA}

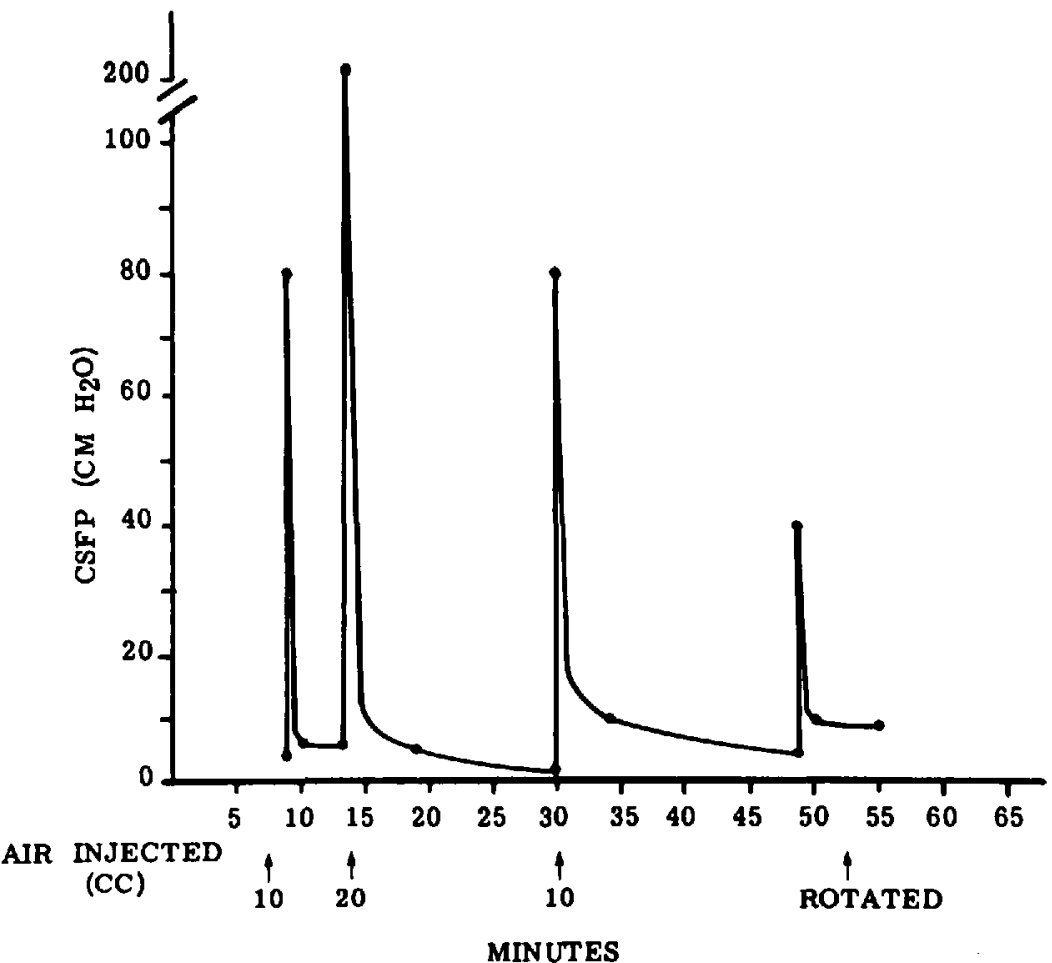

Figure 8. This is the graph (A) and record (B) obtained of CSFP changes during PEG under local anaesthesia. The EKG lead was omitted. The top channel displays respiratory activity, the middle channel arterial pressure and the bottom channel the CSFP. Because of the high pressures reached the tracing was recalibrated at three different pressure settings of 200,80 and $40 \mathrm{~cm} \mathrm{H}_{2} \mathrm{O}$.
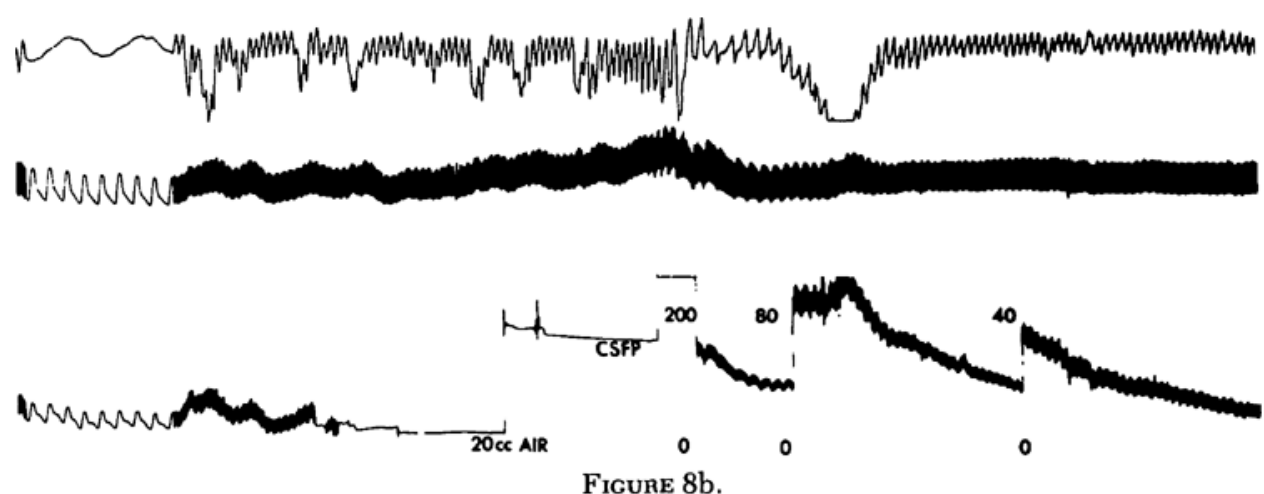

cerebral venous reservoir and the more distensible dural sac is exhausted. Although intracranial pressure may be little affected, any further increase in intracranial volume, such as during air encephalography, results in alarming increases in cerebrospinal fluid pressure and this increased pressure remains elevated until the 
injected gas is absorbed. This much slower and dramatically different pressure buffering capacity was observed in three patients who displayed a delayed rate of return to baseline values after air injection. We are presently investigating the relationship between the delayed time course for return of cerebrospinal fluid pressure to pre-injection levels, and disorders in CSF absorptive mechanisms in these patients. Lorenzo, ${ }^{22}$ in his study of CSF dynamics in hydrocephalus, characterized two types of absorptive defects and speculated about the role of the tubular microvilli. Our coincident finding of a slow fall in cerebrospinal fluid pressure and absence of the stepwise fall following air injection suggests a diagnostic test for normal pressure hydrocephalus.

The one patient who did not receive a general anaesthetic had remarkably elevated CSF pressure following intrathecal air injection. Although there was no preinjection evidence of increased intracranial pressure, it is clear that the pressure buffering capacity had been consumed by her slowly-enlarging ventricles in an otherwise atrophied brain. When the cerebrospinal fluid pressure rose over 200 $\mathrm{cm} \mathrm{H}_{2} \mathrm{O}$ the blood pressure also rose, and the patient became apnoeic and flushed. As the CSF pressure slowly fell, both blood pressure and respiratory pattern returned to normal. Although we did not calculate cerebral perfusion pressure, it is likely that this elevated intracranial pressure resulted in a cerebral perfusion pressure less than 40 torr, and a subsequent period of cerebral hypoxia. ${ }^{23}$ Risberg $^{24}$ interprets this exaggerated response as a critical intracranial pressure phenomenon. At this critical intracranial pressure, probably close to arterial pressure, a dilatation of cerebral arteries occurs, and the draining veins are obstructed by the combined volumes of CSF and increased cerebral blood. This increase in intracranial blood volume cannot be immediately compensated for, and the intracranial pressure rises rapidly. During this high pressure period, CSF is forced from the cranial cavity and the intracranial pressure falls to another critical level, at which arterial vasomotor tone is restored and the venous obstruction released. This results in a sudden fall in both cerebrospinal fluid pressure and regional cerebral blood volume.

During the halothane/oxygen anaesthetic, cerebrospinal fluid pressure was not elevated. This may be due to the fact that the patient was spontaneously hyperventilating with $\mathrm{PCO}_{2}$ of $33.9,22$ and 28.5 torr. Also, no nitrous oxide was used as an adjunct to anaesthesia. The one startling event was the gradual but persistent fall in blood pressure when the patient was in the brow-down position. On rotating the patient to the brow-up position the blood pressure rose almost immediately. It is probable that this postural hypotension resulted from venous pooling in the dependent extremities, and could explain the immediate response to the change in position by "auto-transfusion" of pooled circulating volume.

It is also interesting that several patients developed "acute tolerance"25 to the thiopentone, awakening with blood levels higher than those recorded during the anaesthetic.

We conclude that thiopentone and lidocaine intravenous infusion provides a safe and effective anaesthetic for pneumoencephalography, and avoids some of the problems associated with other anaesthetic agents and nitrous oxide. 


\section{SUMMARY}

A solution of $1.5 \mathrm{gm}$ thiopentone and $0.2 \mathrm{gm}$ lidocaine in $500 \mathrm{cc}$ normal saline was used successfully as the general anaesthetic for pneumoencaphalography in 23 consecutive, unselected patients. The depth of anaesthesia was effectively controlled by regulating the rate of infusion of this intravenous solution. Spontaneous respirations were adequate, blood pressures were well maintained and no arrhythmias were recorded during the procedures, despite the extreme positional changes to which the patients were subjected.

The technique was assessed with continuous monitoring of arterial blood pressure, lumbar cerebro-spinal fluid pressure, respirations, electrocardiogram, arterial blood gases and serum drug levels of thiopentone and lidocaine.

We believe the technique to be more satisfactory than other reported anaesthetic techniques for pneumoencephalography.

Some observations about cerebro-spinal fluid pressures during pneumoencephalography, and their relationship to altered cerebro-spinal fluid dynamics, are also made.

\section{RÉSUMÉ}

Chez 23 malades consécutifs et non choisis, comme mélange anesthésique pour pneumoencéphalographie, nous avons utilité avec succès une solution de $1.5 \mathrm{gm}$ de thiopentone et de $0.2 \mathrm{gm}$ de lidocaïne dans un sérum salé de $500 \mathrm{cc}$. Nous avons controlé efficacement le niveau d'anesthésie en réglant la vitesse du goutte à goutte de la solution I.V. La respiration spontanée était adéquate, les pressions se sont bien maintenues, on n'a noté aucune arythmie durant l'opération, malgré les changements extrêmes de position infligés aux malades.

Nous avons évalué la technique en faisant un controle continu de la tension artérielle, de la pression lombaire du liquide céphalo-rachidien, des respirations, de l'électrocardiogramme, des gaz artériels et des dosages sanguins des taux de thiopentone et de lidocaine.

Nous sommes d'avis que cette technique procure plus de satisfaction que d'autres techniques d'anesthésie publiées pour pneumoencéphalographie.

Nous avons également fait des remarques concernant les pressions du liquide céphalo-rachidien durant la pneumoencéphalographie et leur éventuelle influence sur la dynamique du liquide cephalo-rachidien.

\section{ACKNOWLEDGMENTS}

We are very grateful to Astra Chemicals Limited and Abbott Laboratories Limited for estimation of blood drug values, to Mrs. C. Thomson for her generous assistance, and to Miss Tanter and colleagues in the Department of Anaesthesia, Wellesley Hospital. 


\section{BIBLIOGRAPHY}

1. Saidman, L.J. \& Eger, E.I. Change in cerebrospinal fluid pressure during pneumoencephalography under nitrous oxide anaesthesia. Anesthesiology 26: I (1965).

2. Gondon, E. \& Greitz Effect of nitrous oxide on cerebrospinal fluid pressure during pneumoencephalography. Brit. J. Anaesth. 42:2 (1970).

3. Wolfson, B., Siker, E.S., Wible, L., \& Dubnansky, J. Pneumoencephalography using neuroleptanalgesia. Anesth. \& Analg. 47: 14 (1968).

4. Edwards, J.C. \& Flowerdew, G.D. Diazepam and local anaesthetic for lumbar air encephalography. Brit. J. Anaesth. $42: 999$ (1970).

5. Conssen, G., Groves, E.H., Gomez, S., \& Allen, R.J. Ketamine: its place in anesthesia for neurosurgical diagnostic procedures. Anesth. \& Analg. 48: 181 (1969).

6. Gardner, A.E., Olsen, B.E., \& Lichtrger, M. Cerebrospinal fluid pressure during dissociative anesthesia with ketamine. Anesthesiol. 35: 226 (1971).

7. Wyte, S.R., Shapiro, H.M., Turner, P., \& Harris, A.B. Ketamine-induced intracranial hypertension. Anesthesiology 36: 174 (1972).

8. Campkin, T.V. \& Tuhner, J.M. Blood pressure and C.S.F.P. studjes during lumbar air encephalography. Brit. J. Anaesth. 44: 849 (1972).

9. Hunten, A.R. Thiopentone supplemented anaesthesia for neurosurgery. Brit. J. Anaesth. 44: 506 (1972).

10. Steinhaus, J.E. \& Gaskin, L. A Study of intravenous lidocaine as a suppressant of cough reflex. Anesthesiol. 24: 285 (1963).

11. de Clive-Lowe, S.G., Desmond, J., \& North, J. Intravenous lignocaine anaesthesia. Anesthesia. 13: 138 (1958).

12. KimmeY, J.R. \& Steinhaus, J.E. Cardiovascular effects of procaine and lidocaine during general anesthesia. Acta Anaesth. Scand. 3: 9 (1959).

13. Austen, W.G. \& Moran, J.M. Cardiac and peripheral vascular effects of lidocaine and procainomide. Amer. J. Cardiol. 16: 701 (1965).

14. Johfeldt, L., Lofstrom, B., Pernow, B., Persson, B., Wahren, J., \& Widmon, B. The effect of local anesthetics on the central circulation and respiration in man and dog. Acta Anaesth. Scand. 12: 153 (1968).

15. Косн-Weser, J. Serum drug concentrations as therapeutic guides. New Eng. J. Med. 287: $227(1972)$

16. Adams, R.W., Gronert, G.A., Sundt, Jr., T.M., \& Michenfelden, J.D. Halothane, hypocapnia and cerebrospinal fluid pressure in neurosurgery. Anesthesiology 37: 510 (1972).

17. Wolfson, B., Sixer, E.S., \& Gray, G.H. Post pneumo-encephalography headache. Anesthesia 25: 328 (1970).

18. Du Boulay, G. Specialization broadens the view. The significance of a C.S.F. pulse. Clin. Radiol. 23: 401 (1972).

19. Welch, K. \& Friedman, V. The Cerebrospinal fluid valves. Brain 83: 454 (1960).

20. Hulme, A. \& Cooper, R. Changes in intracranial pressure and other variables during the induction of general anesthesia. Proc. Roy. Soc. Med. 65: 10, 17 (1972).

21. Shapiro, H.M., Wyte, S.R., Harris, A.B., \& Galindo, A. Acute intraoperative intracranial hypertension in neurosurgical patients. Anesthesiology 37: 399 (1972).

22. Lorenzo, A.R., Pace, L.K., \& Watters, G.V. Relationship between cerebrospinal fluid formation, absorption and pressure in human hydrocephalus. Brain 93:679 (1970).

23. Fitch, W., Barker, J., Jennett, W.B., \& McDowall, D.G. The influence of neuroleptanalgesic drugs on cerebrospinal fluid pressure. Brit. J. Anaesth. 41:800 (1969).

24. Risberg, J., Lundberc, N., \& Ingvar, D.H. Regional cerebral blood volume during acute transient rises of the intracranial pressure. J. Neurosurg. 31: 303 (1969).

25. Maynert, E.W. \& Klingman, G.I. Acute tolerance to intravenous anesthetics in dogs. J. Pharmacol. Exp. Therap. 128: 192 (1960).

26. EdHons, G.A. Determinations of lidocaine in whole blood by gas chromatography. C.A.S.J. 18, 2: 189 (1971). (The method now used is slightly modified, using isopentane rather than ether.) 